\title{
OS ECOSSISTEMAS DUNARES E A LEGISLAÇÃO AMBIENTAL BRASILEIRA
}

\section{THE DUNE ECOSYSTEMS AND THE BRAZILIAN ENVIRONMENTAL LEGISLATION}

\author{
Mônica Virna de Aguiar Pinheiro \\ Doutoranda em Ciências Marinhas Tropicais \\ UFC \\ monivirna@yahoo.com.br \\ Marcelo Martins Moura-Fé \\ Doutorando em Geografia \\ UFC \\ mourafe.marcelo@yahoo.com.br \\ Eduardo Marcelo de Negreiros Freitas \\ Defensor Público Federal \\ FANOR \\ eduardomnfreitas@hotmail.com
}

\section{Resumo}

O Brasil abrange diversos ecossistemas, dentre eles, os dunares, um complexo natural dotado de feições interdependentes e interligadas, dentre elas, as dunas móveis e fixas, planície de deflação e as praias. Todavia, a atual legislação ambiental brasileira no âmbito federal parece não entender e/ou considerar relevantes tais características, tendo em vista a Lei Federal n ${ }^{\circ}$ 12.651-2012 (Código Florestal) que apresenta as dunas fixas como uma feição separada das demais, caracterizando-as como Áreas de Preservação Permanente, e as demais feições do ecossistema dunar, não. $\mathrm{O}$ trabalho apresenta conceitos científicos e fundamentação jurídica para que as dunas sejam tratadas enquanto um ecossistema e que este seja protegido legalmente no âmbito federal sob essa premissa fundamental, sob os riscos de que mesmo a pretensa proteção legal setorizada esteja comprometida pelas formas históricas e atuais de uso e ocupação desse ecossistema no país.

Palavras Chave: Ecossistemas Dunares, Legislação Ambiental, Meio Ambiente, Áreas de Preservação Permanente e Código Florestal Brasileiro.

\footnotetext{
Abstract

Brazil covers various ecosystems, including the dune, a complex endowed with natural features interdependent and interconnected among them, mobile and fixed dunes, deflation plains and beaches. However, the current Brazilian environmental legislation at the federal level does not seem to understand and / or consider such relevant features, in view of the Federal Law $N^{\circ}$ 12.651-2012 (Forestry Code) which presents the fixed dunes as a feature separate from the others, characterizing them as Permanent Preservation Areas and other features of the dune ecosystem, no. The paper presents scientific concepts and legal reasoning that the dunes are treated as an ecosystem and that this is protected under federal law under this fundamental premise, under the same 
risks that the alleged sectorized legal protection is compromised by forms of historical and current use and occupation of the ecosystem in the country.

Key Words: Dune ecosystems, Environmental Law, Environment, Permanent Preservation Areas and the Brazilian Forest Code.

\section{Introdução}

O litoral brasileiro abrange diversos ecossistemas e dentre estes, encontram-se os campos de dunas móveis, os quais podem ser verificados nas mais diversas formas, extensões e caracterizações espaciais. $\mathrm{O}$ ambiente de dunas pode ser encontrado desde $\mathrm{o}$ litoral do estado do Rio Grande do Sul (região sul do país) ao Nordeste do Brasil. Contudo, mesmo ocorrendo em quase todo o litoral brasileiro, seu predomínio se dá de forma mais enfática ao longo da zona litorânea do nordeste brasileiro, com as maiores exposições ocorrendo entre os estados do Rio Grande do Norte e do Maranhão, passando, por conseguinte, no contexto territorial do estado do Ceará.

Conceitualmente, um ecossistema é uma associação autossustentável entre plantas, animais e as partes abióticas de seus ambientes físicos. A própria biosfera terrestre é uma coleção de ecossistemas dentro do limite natural da atmosfera e crosta terrestre. Mais precisamente, ecossistemas naturais são sistemas abertos tanto para a energia solar como para matéria, com praticamente todos os limites seus funcionando como zonas de transição e não como demarcações nítidas (CHRISTOPHERSON, 2012).

Partindo desta conceituação, fica clara a necessidade de tratar os ecossistemas nos seus aspectos interrelacionais, ao passo que, conforme Christopherson (2012), um ecossistema é um complexo de muitas variáveis, todas funcionando independentemente, mas ao mesmo tempo, interligadas, com complicados fluxos de energia e matéria.

Os campos de dunas se notabilizam tanto por sua dinâmica ambiental, sujeita e condicionada a diversos elementos naturais, os quais serão apresentados mais adiante, quanto pela diversidade de formas que os compõem e que se relacionam para derivar nas características singulares que cada campo dunar costuma apresentar.

Em função dessas características, segundo Christopherson (2012), os campos de dunas, ou dito de outra forma, os ecossistemas dunares, assim como diversos outros ecossistemas, tem no conceito de mudança algo fundamental para entender a sua estabilidade ou instabilidade. 
Embora as dunas e suas feições correlatas se caracterizem pela dinâmica intensa e pelo inter-relacionamento estreito entre si, a atual legislação ambiental brasileira no âmbito federal não tem levado em consideração tais características.

A Lei Federal $n^{\circ}$ 12.651/2012 (BRASIL, 2012a) em seu art. $4^{\circ}$, apresenta como Áreas de Preservação Permanente (APPs) apenas as restingas, como fixadoras de dunas ou estabilizadoras de manguezais, onde entende-se que há a proteção das dunas fixas, mas sem a proteção explícita das demais formas de relevo ocorrentes nos ecossistemas dunares.

Daí faz-se um questionamento: como proteger uma feição natural, caracterizando-a como uma Área de Preservação Permanente sem garantir a proteção das feições correlatas que garantem a dinâmica e o equilíbrio do ecossistema dunar? Antes de entrar nessa discussão, vale explanar com mais propriedade os processos genéticos, migratórios e de estabilização dos campos de dunas, os quais corroboram o entendimento dessas feições enquanto um ecossistema.

\section{Processos Genéticos dos Campos de Dunas}

\section{A Atuação das Correntes Litorâneas e o Fomento da Deriva de Sedimentos}

As correntes litorâneas são os verdadeiros agentes transportadores de areias na zona litorânea imersa, se constituindo como um dos mais importantes agentes de remobilização de sedimentos, sendo responsáveis pelo transporte de material ao longo da costa a partir de uma fonte, tal como um rio. Constituem, também, o grande mecanismo de circulação responsável pela manutenção da estabilidade e equilíbrio dos ambientes praiais (TESSLER e MAHIQUES, 2003).

Há que se ressaltar que qualquer modificação introduzida pela sociedade no sistema de deriva litorânea afeta o equilíbrio de estoque natural de areias ao longo das praias, influenciando, por conseguinte, nas taxas de erosão ou deposição. Por exemplo, obras de construção civil, como molhes, portos, aterros e dragagens, têm sido responsáveis pela intensificação da erosão de muitos trechos ao longo da costa brasileira.

As correntes litorâneas transportam significativa quantidade de sedimentos que são depositados na faixa de praia pela atuação das ondas e marés. Ao se depositarem na 
faixa de praia, os sedimentos poderão ser remobilizados pelos ventos e, consequentemente, formar os campos de dunas.

\section{O Caminho dos Sedimentos na Faixa Litorânea: o mecanismo de Transpasse}

\section{Costeiro}

No Ceará, um importante elemento dinâmico constituído por células sedimentares é formatado pelas pontas litorâneas ou promontórios, e sua presença corresponde normalmente, dentro da zona litorânea, à fronteira entre um setor terminal de uma célula sedimentar (à montante) e um setor proximal de uma nova célula (PINHEIRO, 2009).

As células litorâneas compreendem segmentos espaciais com balanço sedimentar, sendo relativamente autônomas em relação aos segmentos adjacentes. Apesar disso, as células sedimentares se comunicam através do transpasse, ou mecanismo de bypass de sedimentos (PASKOFF, 1996), que pode ser tanto costeiro, condicionado pelos ventos, como litorâneo, nesse caso, controlado pelas ondas e correntes litorâneas (CLAUDINO-SALES, 2005) (Figura 1).

O transpasse costeiro ocorre sobre a zona on-shore (daí a designação "costeira”), quando se formam dunas com as areias interceptadas à barlamar de pontas litorâneas. Com o passar do tempo, as areias acumuladas acabam transpondo o obstáculo, dando início ao transpasse litorâneo por ação das correntes litorâneas. Os dois em conjunto, minimizam a erosão das praias em células sedimentares controladas por pontas litorâneas (PINHEIRO, 2009).

Ao mesmo tempo em que as pontas litorâneas interditam o transpasse litorâneo de sedimentos, ainda segundo Pinheiro (2009), elas induzem o transpasse costeiro de areias por intermédio da migração de dunas transgressivas que atravessam a zona costeira cruzando os promontórios.

Esse mecanismo natural de migração de sedimentos em promontórios também torna-se relevante do ponto de vista ambiental ao proporcionar o equilíbrio praial de todos os setores à jusante do promontório. Ao se romper esse equilíbrio, como por exemplo, ocupando os setores de promontórios, sejam eles on-shore ou off-shore, onde ocorre o transpasse de sedimentos, toda a faixa litorânea estará comprometida a sérios 
riscos de intensificação dos processos erosivos e, consequentemente, perdas sucessivas e relevantes de faixa de praia.

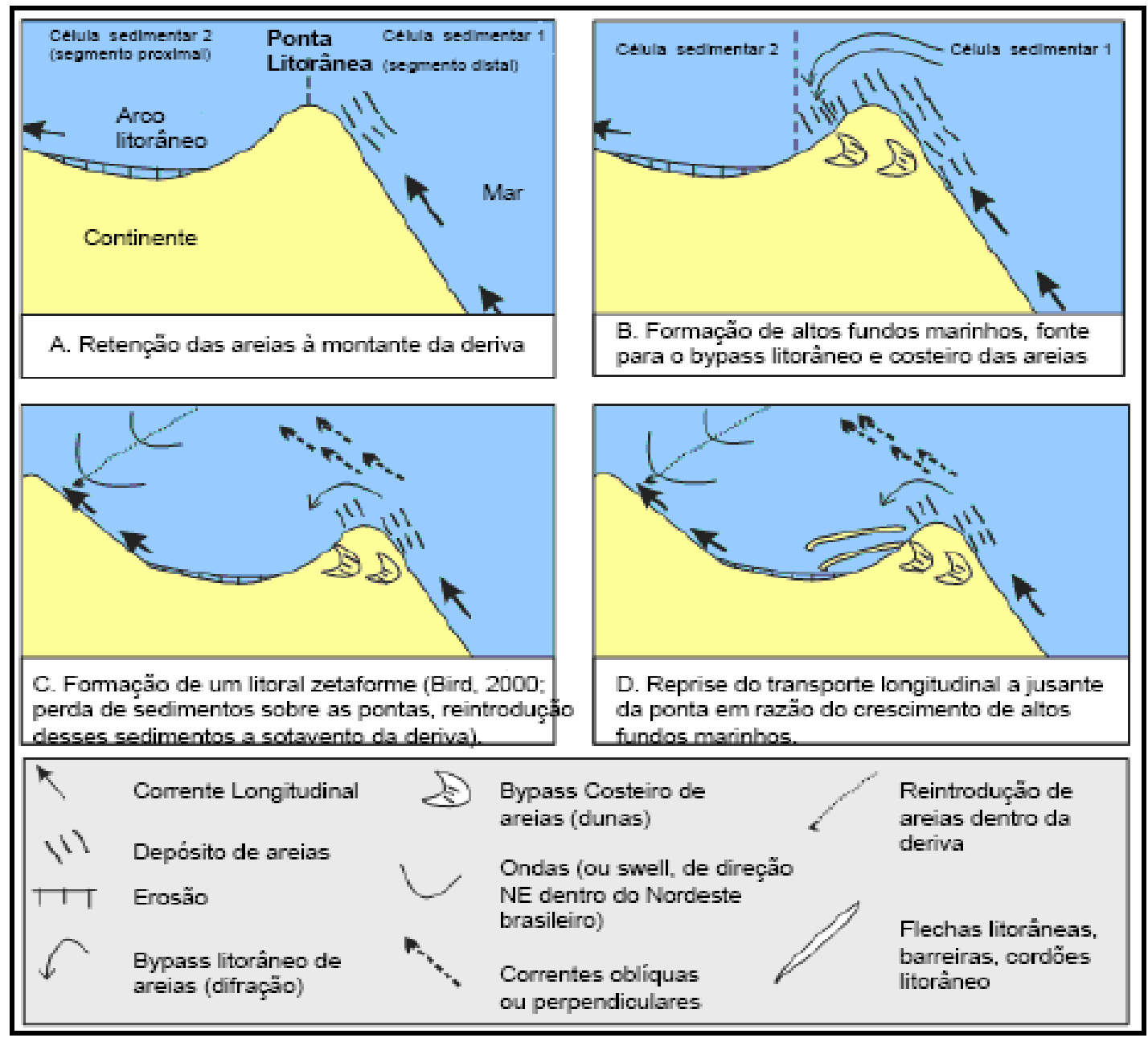

Figura 1: Desenho esquemático do processo de transpasse de sedimentos ao longo de obstáculos como pontas litorâneas com a que ocorre em Fortaleza (Mucuripe).

Adaptado de Claudino-Sales (2002).

\section{As Correntes Eólicas}

O vento, dentre os elementos climáticos atuantes na faixa litorânea, assume papel relevante na morfogênese de campos de dunas.

Sua atuação ocorrer depois que a areia movimentada por ondas e correntes é depositada na praia e exposta diretamente ao ar. Dependendo das condições climáticas e granulométricas intrínsecas, depois de seca, a areia poderá ser movimentada pelos ventos, normalmente por saltação ou arraste. Assim, quando os ventos sopram do mar eles acabam por levar as areias das praias em direção ao continente, desenvolvendo sob 
diferentes padrões de velocidade os campos de dunas, os quais, por sua vez, terão sua orientação retratando a direção dos ventos dominantes na região costeira (VILLWOCK et al., 2005) e corroborando a importância desse agente dinâmico.

A orientação dos campos de dunas no Ceará, por exemplo, apresenta-se em concordância com o regime eólico predominante: a velocidade dos ventos de direção NE com menor capacidade de formação de dunas, assim como uma maior umidade no primeiro semestre do ano, dificulta a mobilização das areias para SW. Assim, de maneira geral, não ocorre campo de dunas no estado do Ceará de direção nordestesudoeste (PINHEIRO, 2009).

\section{Migração e a Formação das Atuais Gerações de Dunas}

\section{A Fonte de Sedimentos: As Praias}

No contato com as águas do Oceano Atlântico, demarcando o contato mais externo da zona costeira cearense, ocorre as praias. Associados a estas feições, podem ocorrer cordões rochosos situados paralelamente à faixa de praia, denominados de rochas de praia (ou beachrocks).

A praia pode ser conceituada como a zona perimetral de um corpo aquoso (seja este um lago, mar ou oceano), composta de material inconsolidado, em geral arenoso, ou mais raramente composta de cascalhos, conchas de moluscos etc.; que se estende desde o nível de baixamar média até a linha de vegetação permanente (limite de ondas de tempestade), ou onde há mudanças na fisiografia, como as zonas de dunas ou de falésias (SUGUIO, 1998).

Na zona costeira do Ceará, as praias comumente formam um depósito contínuo, alongado por toda a extensão da costa, desde a linha de maré baixa até a base das dunas (SOUZA, 1988) frontais, falésias ou estruturas rochosas. Tal continuidade, por vezes, é recortada pelos cursos d'água que alcançam a costa. É formada pela acumulação de sedimentos quaternários holocênicos e apresentam uma estrutura de baixa inclinação definida pela interação dos agentes constituintes do processo. Esta interação resulta numa configuração morfológica predominantemente plana a suave ondulada, que se modifica nas áreas de campos de dunas e planícies de deflação (Figura 2), onde o relevo mostra-se mais irregular e elevado. 
As praias constituem-se como a primeira etapa no continente de gênese das dunas, ao passo que os sedimentos depositados pelas ondas, notadamente com a ocorrência das marés baixas, são depositados sobre a superfície praial (pós-praia), disponibilizados para a ação dos agentes eólicos, os quais poderão transportar os sedimentos para o interior do continente. Durante o transcorrer dessa migração tem-se o sucessivo acúmulo das areias (GONÇALVES et al., 2003) que vão formar as dunas.

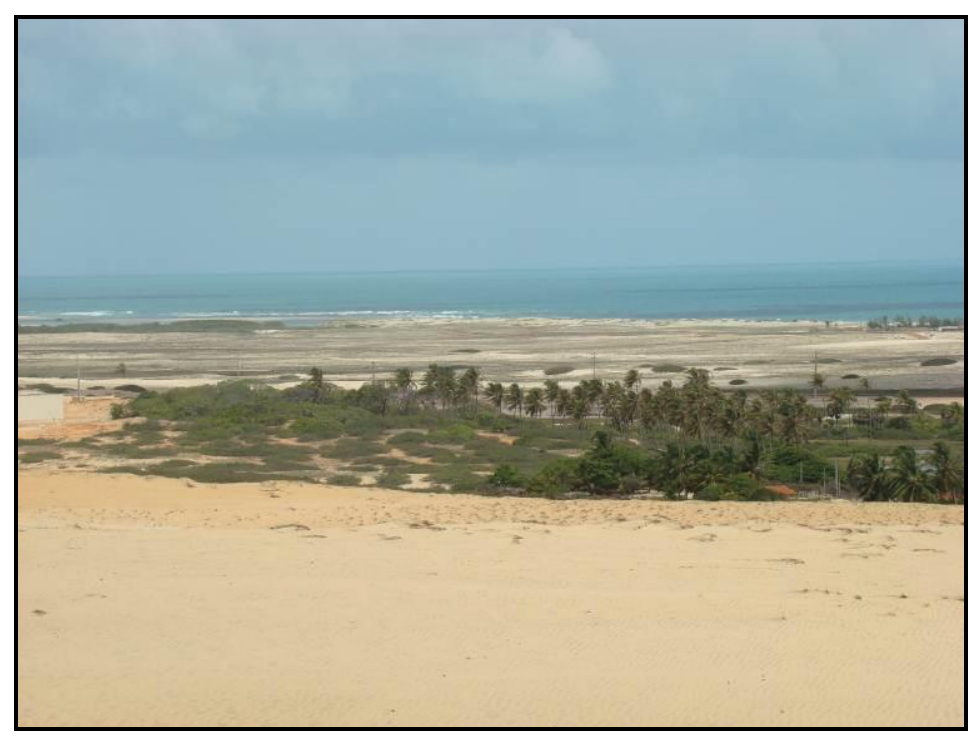

Figura 2: Panorama da planície de deflação, parcialmente recoberta por vegetação na praia do Morro Branco (município de Beberibe). Foto: Mônica Pinheiro (Fev, 2009).

\section{A Zona de Migração: Planície de Deflação}

Conceitualmente, as planícies de deflação são superfícies planas ou ligeiramente inclinadas, que se estendem desde o limite da maré alta (limite continental das praias) até a base dos campos de dunas em direção ao continente. Nestas superfícies predomina a remoção de sedimentos pelos processos eólicos, com formação de feições residuais (CEARÁ, 2006).

Estas feições ocorrem em praticamente todo o litoral nordestino, comumente apresentando características topográficas planas, com suave caimento na direção da faixa de praia e constituem-se como a feição que faz a transição entre as praias e os campos de dunas, mais precisamente, o setor de formação e ocorrência inicial das dunas móveis (PINHEIRO, 2009).

Justamente por situar-se em contato com ambas as feições, sobre essa feição tem-se o processo de migração dos sedimentos que vem das praias através da ação dos 
ventos e que vão alimentar os campos de dunas. Portanto, nos setores costeiros onde ocorrem as planícies de deflação, essas caracterizam-se sine qua non como uma feição fundamental para o processo de fomento das atuais gerações de dunas.

Além disso, nos setores de planície de deflação tem-se a formação de pequenas dunas, móveis ou semi-fixas e lagoas freáticas que se formam predominantemente nos períodos de concentração de chuvas que compõem uma rica biodiversidade e singular paisagem natural. Ao se ocupar os setores de planície de deflação a alimentação sedimentar, ou seja, a migração dos sedimentos para as dunas será interrompida diminuindo a possibilidade de formação de novas dunas no setor ocupado (PINHEIRO, 2009).

\section{O Encontro dos Sedimentos: As Dunas Móveis}

Ao se formarem, os corpos dunares ganham contornos distintos, os quais se definem através de diferenciações estreitamente relacionadas à direção do vento dominante e ao clima da região, à granulometria dos sedimentos, à conformação da superfície percorrida pelos sedimentos desde sua exposição na faixa de praia, à ação dos ventos na faixa de praia e à localização dessas dunas dentro do segmento costeiro (PINHEIRO, 2009).

As grandes famílias de formas dunares caracterizam-se quanto à sua morfologia em: dunas móveis, dunas semifixas, dunas fixas, os eolianitos (ou dunas cimentadas) e as formas de deflação. Especificamente, as dunas móveis caracterizam-se por um transporte permanente dos grãos de areia, resultando em uma permanente migração e modificação das formas dunares.

Além disso, as dunas móveis caracterizam-se pela ausência de vegetação ou pela fixação de um revestimento pioneiro, o qual detém ou atenua os efeitos da dinâmica eólica, responsável pela migração (PINHEIRO, 2009; MOURA-FÉ, 2008).

Há também a via antrópica de transformação das feições dunares. Dunas móveis quando intervencionadas, ou são retirados por completo os sedimentos, desmonte de dunas, ou as mesmas são fixadas artificialmente (brita, palhas de coqueiro etc.) como forma de conter a migração de sedimentos. Isso vem ocorrendo de forma bastante corriqueira nas obras de parques eólicos na zona costeira, que para evitarem prejuízos 
em seus equipamentos e vias de acesso promovem a fixação dos campos de dunas móveis onde se instalaram (MOURA-FÉ e PINHEIRO, 2013).

A planície costeira do estado do Maranhão, nordeste do Brasil possui o maior registro de sedimentação eólica do Quaternário da América do Sul, correspondendo aos campos de dunas livres e fixas que, juntos, alcançam larguras de até $50,0 \mathrm{~km}$, denominados de Lençóis Maranhenses. São compostos de dunas moveis, fixas e semifixas, com predomínio de dunas móveis barcanas e barcanóides, além dos lençóis de areia ou dunas compostas.

No Ceará, as dunas formam cordões quase contínuos que acompanham paralelamente a linha de costa, sendo interrompidos, vez ou outra, por planícies fluviais e fluviomarinhas, por sedimentos mais antigos pertencentes à Formação Barreiras que, por vezes, se projetam até a linha de praia, expondo-se como falésias, ou ainda por promontórios constituídos por litologias mais resistentes (Ponta do Iguape, em Aquiraz e Pedra Furada, em Jijoca de Jericoacoara, por exemplo).

Na região entre o Cabo Búzios e o Cabo Frio observa-se a formação de campos de dunas móveis, únicos em toda a costa fluminense. A ocorrência local dessas dunas está associada, principalmente, à orientação dos ventos predominantes do quadrante Nordeste e a um clima semiárido na região. A expressiva distância do litoral à Serra do Mar diminui os índices de chuvas convectivas e orográficas, criando assim, um enclave de semi-aridez em meio a um clima tropical para o resto do estado do Rio de Janeiro (PEREIRA et al., 2010).

Desta forma, os campos dunares observados entre o Cabo Búzios e o Cabo Frio constituem importante elemento representativo da geodiversidade do estado do Rio de Janeiro, devido às feições geomorfológicas observadas, bem como à sua função na composição da paisagem regional e sua vulnerabilidade frente ao processo de expansão da ocupação urbana (PEREIRA et al., 2010).

Por sua vez, a costa do Rio Grande do Sul possui uma vasta planície costeira, com ventos apropriados e disponibilidade de sedimentos. Como consequência, essa região desenvolveu um dos mais expressivos sistemas eólicos do litoral brasileiro. Dunas eólicas vegetadas e não vegetadas, de idade holocênica, se desenvolvem praticamente ao longo de toda a extensão da linha de costa $(630,0 \mathrm{~km})$ sendo que, em 
certos trechos, o campo eólico transgressivo alcança largura superior a 5,0 km (TOMAZELLI et al., 2003).

\section{Fixação de Dunas e as Gerações Pretéritas}

Ao se aglomerarem e se afastarem da faixa de praia, as dunas móveis tendem a perder mobilidade e ao encontrar obstáculos como foz de rios, falésias, lagoas, entre outros, a se fixarem. Os sedimentos, ao perderem mobilidade, possibilitam a atuação dos processos pedogenéticos e consequentemente o recobrimento vegetal. Esse processo pode durar de dezenas a milhares de anos. Assim, as dunas fixas vão formar um ambiente rico em biodiversidade, fonte hídrica e de proteção da zona costeira.

De maneira geral, pode-se dizer que todas as dunas costeiras estabilizadas atualmente indicam terem tido algum tipo de mobilidade no passado, provavelmente sob regime climático diferente do atual (TSOAR e ARENS, 2003).

\section{Dunas Fixas e Semi-fixas}

Segundo Pinheiro (2009), no tocante às dunas fixas, essas feições são caracterizadas pela imobilidade atual dos sedimentos que as compõem, a partir da colonização por vegetação costeira, a qual, por sua vez, pode alcançar até um porte arbóreo.

As dunas fixas apresentam um recobrimento vegetal pioneiro, que detém ou atenua os efeitos da deflação eólica e podem ser totalmente fixas ou, por vezes, esse recobrimento pode se dar de forma parcial, neste caso, tem-se as chamadas dunas semifixas.

Quando fixas, as dunas apresentam um maior desenvolvimento pedológico associado ao desenvolvimento de uma cobertura vegetal, dando à esta feição uma estabilidade ambiental, ao mitigar a influência dos ventos, fixando-a na paisagem (PINHEIRO, 2009). Figura 3.

As dunas semi-fixas caracterizam-se primordialmente pela sua semi-mobilidade, ou seja, não são totalmente móveis e nem totalmente fixas. Isso ocorre porque essa tipologia de dunas possui partes de sua estrutura coberta pela vegetação, demonstrando que há aporte mais ou menos equilibrado com a saída de sedimentos, de forma a haver mobilidade (dos sedimentos), mas não migração (mudança espacial) do corpo dunar. 
Isto é, o saldo entre entrada (input) e saída (output) de sedimentos é algo que se aproximaria do equilíbrio (PINHEIRO, 2009).

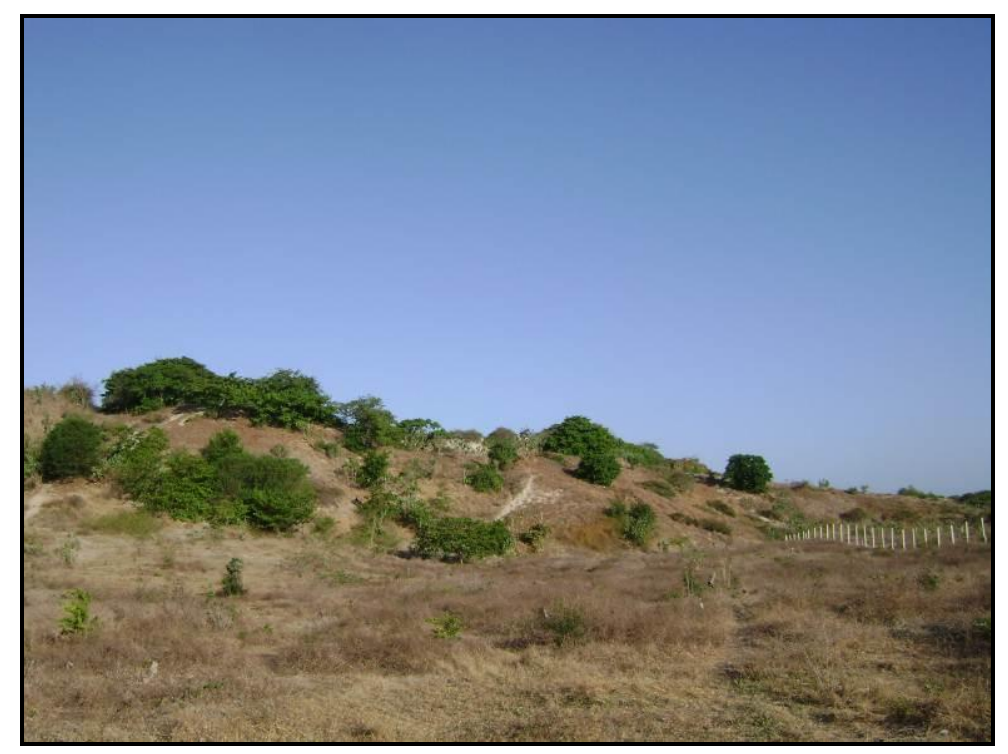

Figura 3: Cordão de Dunas Fixas, Praia do Futuro, Fortaleza, CE. Foto: Mônica Pinheiro (Dez, 2008).

Um dos principais exemplos de dunas semi-fixas são as dunas frontais, as quais ocorrem no limite da faixa de praia, formando uma barreira paralela à praia. Essas dunas possuem significativa importância na proteção da faixa litorânea de marés extremas e ondas de tempestades. Os desequilíbrios associados as alteração antrópicas nas dunas fixas e semi-fixas são relacionados à retirada da vegetação fixadora, podendo causar a remobilização dos sedimentos, perda da biodiversidade formada, além de área de recarga de aquífero.

\section{Eolianitos}

Os eolianitos (Figura 4) representam sedimentos de antigas dunas eólicas que passaram por processo de cimentação carbonática de seus grãos constituintes. Esse tipo de depósito é encontrado em zonas costeiras, sendo composto por areias quartzosas e grande quantidade de carbonato originário de organismos (carbonato biogênico) (CARVALHO et al., 2008). Um eolianito pode ser conceituado como um sedimento consolidado de origem eólica, tais como, os depósitos de antigas dunas (SUGUIO, 1998). 
Estas feições estão distribuídas de forma descontínua ao longo de quase todo o trecho noroeste da costa cearense, numa faixa de terra que varia de algumas dezenas a centenas de metros de largura, sendo mais comuns entre as localidades de Pecém e Acaraú. Tal ocorrência é explicada pela presença de carbonatos na plataforma interna adjacente, próximos da faixa de praia (CARVALHO et al., 2008).

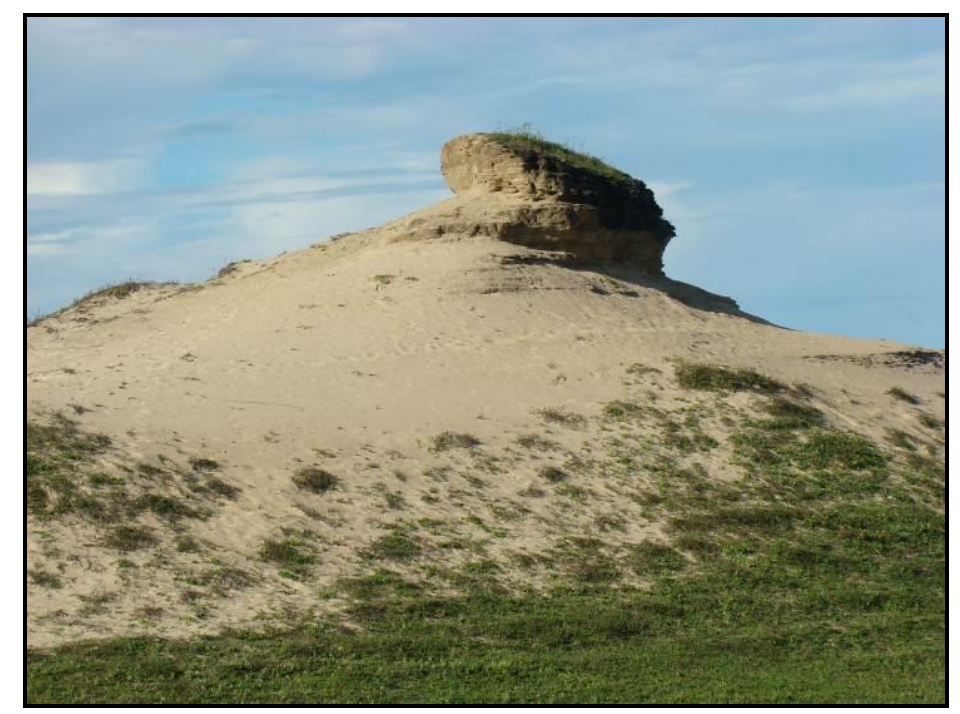

Figura 4: Eolianito isolado na Praia de Paracuru (município de Paracuru, litoral oeste do Ceará). Foto: Marcelo Martins (Mai, 2009).

Os eolianitos, ainda segundo Carvalho et al. (2008), estão distribuídos em faixas oblíquas ao longo da costa, numa distância que varia de 3 a $6 \mathrm{~km}$ da linha de costa, para o seu limite interno. Eventualmente o limite externo desses depósitos situa-se a uma distância de não mais que algumas dezenas de metros, muitas vezes aflorando na praia, quando se apresentam então à disposição da erosão das ondas.

Os afloramentos comumente expõem seções verticais que foram postas em evidência em função da ação abrasiva do vento. Tal processo abrasivo expôs estratos bem delimitados, assim como superfícies com topos tabulares de aspecto ruiniforme, caracterizados pela presença de sulcos orientados na direção do vento principal, segmentos de vertentes íngremes e cristas bastante irregulares, formando-se feições do tipo “yardang” e "zeugen" (CARVALHO et al., 2008).

O caráter frágil dos eolianitos é demonstrado pela suscetibilidade à erosão eólica e à ação antropogênica que eles apresentam. A necessidade da preservação também é indicada pelo fato de existirem inúmeras ocorrências de interesse arqueológico, tais 
como fogueiras e fragmentos de cerâmicos e líticos em geral a eles associados (CARVALHO et al., 2008).

Em função da importância dessa unidade geoambiental, o Plano Estadual do Gerenciamento Costeiro do Ceará transforma, os eolianitos como feição de preservação permanente, no âmbito do território do Estado do Ceará (CEARÁ, 2006).

\section{Paleodunas}

Situadas à retaguarda das dunas recentes, observam-se essas gerações mais antigas de dunas, as quais apresentam o desenvolvimento de processos pedogenéticos (daí serem chamadas de dunas edafizadas), resultando na fixação de um revestimento vegetal de maior porte, além de já não se distinguir facilmente suas formas.

As paleodunas encontram-se comumente no interior da zona costeira, topograficamente planas, o que as confunde com depósitos de sedimentos mais antigos da zona costeira, como a Formação Barreiras. Esse tipo de duna é responsável pela filtração ou alimentação de água doce no aquifero dunas/barreiras, ou seja, uma fonte hídrica de significativa importância dada a escassez de água doce no mundo e principalmente, em zona semi-árida como em parte do nordeste brasileiro.

Um exemplo da justaposição das diferentes feições naturais que compõem o ecossistema dunar pode ser verificado no Mapa Geomorfológico do Litoral Norte do Estado do Ceará (Figura 5).

\section{O Novo Código Florestal Brasileiro}

Até o momento da sua promulgação cerca de 36 projetos de lei tentaram derrubar o Código Florestal. Todavia, apesar das pressões e das inúmeras discussões, em maio de 2012, foi sancionada a Lei Federal n 12.651/2012, que:

Dispõe sobre a proteção da vegetação nativa; altera as Leis ${ }^{\text {os }} 6.938$, de 31 de agosto de 1981, 9.393, de 19 de dezembro de 1996, e 11.428, de 22 de dezembro de 2006; revoga as Leis $\mathrm{n}^{\text {os }} 4.771$, de 15 de setembro de 1965, e 7.754, de 14 de abril de 1989, e a Medida Provisória no 2.166- 67, de 24 de agosto de 2001; e dá outras providências (BRASIL, 2012a). 


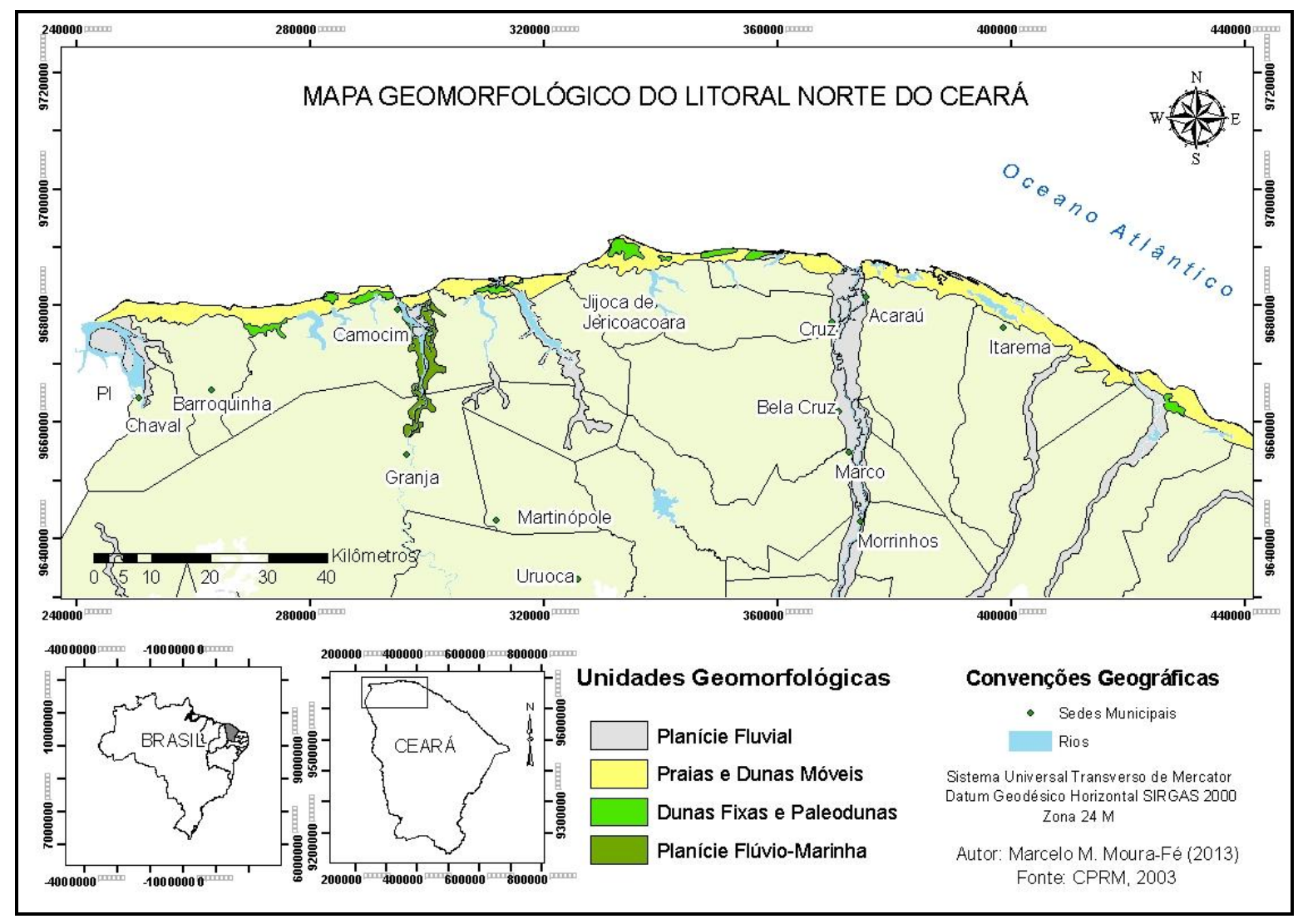

Figura 5: Mapa Geomorfológico do Litoral Norte do Ceará.

A Lei Federal $n^{\circ}$ 12.651/2012, conhecida como o novo Código Florestal Brasileiro, em seu art. $4^{\circ}$, apresenta como Áreas de Preservação Permanente: "VI - as restingas, como fixadoras de dunas ou estabilizadoras de manguezais". Lendo esse inciso, entende-se que há a proteção das dunas fixas.

Observando o art. $3^{\circ}$ da referida lei, mais precisamente em seu parágrafo XVI, onde há o conceito de restinga, lê-se:

XVI - restinga: depósito arenoso paralelo à linha da costa, de forma geralmente alongada, produzido por processos de sedimentação, onde se encontram diferentes comunidades que recebem influência marinha, com cobertura vegetal em mosaico, encontrada em praias, cordões arenosos, dunas e depressões, apresentando, de acordo com o estágio sucessional, estrato herbáceo, arbustivo e arbóreo, este último mais interiorizado (BRASIL, 2012a).

Ou seja, quando ocorrem as restingas há a proteção de praias e dunas, mas não há o entendimento que as praias ou as dunas móveis sejam Áreas de Preservação Geo UERJ - Ano 15, nº. 24, v. 2, $2^{\circ}$ semestre de 2013

ISSN: 1415-7543E-ISSN: 1981-9021

http://www.e-publicacoes.uerj.br/index.php/geouerj 
Permanente fora do âmbito espacial das restingas, tampouco a feição que comumente faz o contato entre as praias e os campos de dunas, a planície de deflação. Dessa forma, há uma proteção legal de algumas feições em contraponto com outras que não são consideradas enquanto APPs, embora todas façam parte de um mesmo ecossistema.

Este (des)entendimento legal implica na possibilidade aberta de ocupação das feições que não são consideradas como APPs. As intervenções sociais, sobretudo, aquelas correlatas à expansão urbana, à especulação imobiliária e/ou à atividade turística, prejudicam a gênese e/ou desenvolvimento dessas feições, causando o inexorável desequilíbrio das mesmas, os quais podem ocorrer em escalas diferenciadas e, nos casos mais significativos, de forma irreversível.

Não custa reiterar que o desequilíbrio das feições naturais não protegidas pela legislação ambiental federal vigente, que se constituem em partes do ecossistema dunar, é sinônimo de desequilíbrio do ecossistema como um todo, portanto, um fator de risco, inclusive, para o equilíbrio das feições que as leis se propõem preservar, dentre elas, as dunas fixas. Dito de outra forma: sem o aporte e a migração de sedimentos, não há dunas a serem fixadas.

Em suma, deve-se analisar sob a égide de um ecossistema único, o qual deve ser mantido ecologicamente equilibrado, sob pena de violação ao que dispõem os princípios do ambiente ecologicamente equilibrado, da prevenção, da precaução e da proteção, que encontram fundamento na Constituição Federal do Brasil e reiterados na Política Nacional do Meio Ambiente - PNMA (BRASIL, 1981).

Aliás, segundo Silva (2011), a aplicação dos princípios da prevenção e precaução permitirá que o acesso à diversidade biológica e aos recursos naturais seja possível sem comprometer o direito das gerações futuras.

Por fim, vale informar que na mesma data de promulgação da Lei Federal $n^{\circ}$ 12.651/2012, dia 25 de maio, foi emitida a Medida Provisória $\mathrm{n}^{\circ} 571$, cujo texto foi integralmente legalizado pela Lei $n^{\circ} 12.727 / 2012$ (BRASIL, 2012b) que por sua vez, não trouxe alterações significativas na conceituação das APPs. A lista permaneceu a mesma. 


\section{Legislação Ambiental dos Estados Costeiros Nordestinos: exceções à regra federal?}

A Lei Federal $n^{\circ}$ 6.938/1981 (que dispõe sobre a Política Nacional do Meio Ambiente - BRASIL, 1981) e a Resolução CONAMA nº 237/1997 (MMA, 2012) postulam que é papel dos estados legislarem em regime de complementaridade em relação à legislação federal, devendo ser tão quanto ou mais restritivos.

Desta forma, embora a atual legislação federal vigente não garanta a proteção legal de todas as feições que compõem os ecossistemas dunares, pode ser papel dos estados garantirem isso.

$\mathrm{Na}$ sequência apresentamos os aspectos mais relevantes verificados nas legislações vigentes dos estados do nordeste brasileiro no tocante à possível proteção dos ecossistemas dunares, ou parte destes.

\section{A Legislação Ambiental Cearense}

A Constituição do Estado do Ceará, promulgada em 05 de outubro de 1989, em seu capítulo II, art. 23 cita que:

As praias são bens públicos de uso comum, inalienáveis e destinadas perenemente à utilidade geral dos seus habitantes, cabendo ao Estado e a seus municípios costeiros compartilharem das responsabilidades de promover a sua defesa e impedir, na forma da lei estadual, toda obra humana que as possam desnaturar, prejudicando as suas finalidades essenciais, na expressão de seu patrimônio natural, histórico, étnico e cultural, incluindo, nas áreas de praias:

(...)

III - restingas e dunas;

(...)

VI - promontórios, costões e grutas marinhas;

VII - sistemas fluviais, estuários e lagunas, baías e enseadas (BRASIL, 1989).

Em seu parágrafo único, o mesmo art. 23 apresenta a delimitação de uma faixa de largura mínima de 33,0 metros entre a linha de maré máxima local e o primeiro logradouro público ou imóvel particular decorrente de loteamento aprovado pelo Poder Executivo Municipal (CEARÁ, 1989). 
Apesar de avançar no tratamento mais abrangente dos ecossistemas dunares, ao tratar as restingas, dunas e, sobremaneira, as praias, não há a proteção explícita das demais feições que compõem esse ecossistema.

Outro aspecto considerável é o conceito das praias apresentado por Ceará (2006), que diz:

\footnotetext{
Áreas cobertas e descobertas periodicamente pelas águas, acrescidas das faixas subseqüentes de material detrítico, tal como areias, cascalhos, seixos e pedregulhos, até o limite onde se inicie a vegetação natural ou, em sua ausência, onde comece um outro ecossistema.
}

Como se observa, há um entendimento compartimentado entre as praias e as demais feições situadas em contato, como as dunas frontais, a planície de deflação e/ou os campos de dunas móveis, reforçando o caráter fragmentado na abordagem e proteção dos ecossistemas dunares.

Especificamente com relação ao tipo de duna eolianito, o plano estadual de gerenciamento costeiro, lei $\mathrm{n}^{\mathrm{o}} 13.796 / 2006$, em seu art. 14, resolve tornar de preservação permanente os eolianitos contidos na zona costeira do estado, feição até então vulnerável dentro do contexto litorâneo cearense. Uma decisão compartimentada, mas que não deixa de ser relevante na proteção desse frágil e importante ambiente dentro da zona costeira cearense.

\section{As Paisagens Notáveis do Maranhão e o Pequeno Litoral do Piauí}

A Lei Estadual no 5.405, de 08 de abril de 1992 (MARANHÃO, 1992), que institui o Código de Proteção de Meio Ambiente e dispõe sobre o Sistema Estadual de Meio Ambiente e o uso adequado dos recursos naturais do Estado do Maranhão, em seu artigo 54, cita: “Art. 54 - Consideram-se de preservação permanente: (...) II - as restingas; III - as dunas; (...) VI - as paisagens notáveis”.

Conforme se observa, a referida lei estadual data de antes da promulgação do atual código florestal, e cita que as restingas e, sobretudo, as dunas são APPs, sem fazer a distinção entre dunas móveis ou fixas.

Além disso, o parágrafo VI, que cita como APPs as paisagens notáveis, abre espaço para o entendimento de que, por exemplo, todo um campo de dunas, incluindo as dunas móveis, fixas, planícies de deflação, lagoas, as praias, sejam consideradas de 
forma integral e conjunta, como APPs, havendo, desse modo, a possibilidade de proteção legal do ecossistema dunar.

Um exemplo significativo do próprio estado do Maranhão são os lençóis maranhenses, um imenso campo de dunas protegido legalmente por se constituir como uma unidade de conservação do tipo Parque Nacional, criada em 1981, mas que, muito provavelmente poderia ser protegida com base no referido parágrafo VI da Lei Estadual $\mathrm{n}^{\circ} 5.405 / 1992$.

Por sua vez, o estado do Piauí, conforme a Lei n 4.854, de 10 de Julho de 1996, que dispõe sobre a Política de Meio Ambiente (PIAUÍ, 1996), nada cita a respeito das Áreas de Preservação Permanente, conceito, aliás, ausente nos demais diplomas legais desse estado.

\section{Rio Grande do Norte, Paraíba e Pernambuco: as Dunas no Litoral Oriental Brasileiro}

O estado do Rio Grande do Norte, por meio da Lei $\mathrm{n}^{\circ}$ 6.950, de 20 de agosto de 1996, que dispõe sobre o Plano Estadual de Gerenciamento Costeiro e dá outras providências (RIO GRANDE DO NORTE, 1996), mais precisamente no art. 20, diz que são áreas de preservação, os ecossistemas frágeis que compõem a Reserva da Biosfera da Mata Atlântica, tais como: "I - as dunas, com ou sem cobertura vegetal; II - as restingas; III - os manguezais; IV - os brejos e áreas úmidas; e, V - as matas ciliares". Portanto, trata as dunas móveis e as fixas como áreas a serem protegidas, além das restingas.

Todavia, abrindo um precedente para ocupação dessas áreas, ainda no art. 20 diz que: "§ $1^{\circ}$. As atividades potencialmente degradadoras a serem desenvolvidas nessas áreas, deverão ser, obrigatoriamente, objeto de licenciamento ambiental pelo órgão estadual competente, cabendo, quando for o caso, o Estudo de Impacto Ambiental".

Contudo, segundo o $\S 2^{\circ}$. O licenciamento das atividades será realizado com base nas normas e critérios estabelecidos no Zoneamento Ecológico-Econômico, sem prejuízos das demais normas específicas federais, estaduais e municipais. Sendo assim, a ocupação desses setores estaria condicionada pela Lei Federal no 12.651/2012. 
Por sua vez, o estado da Paraíba traz na sua Constituição Estadual (PARAÍBA, 1989), mais precisamente no art. 227, parágrafo IX: designar os mangues, estuários, dunas, restingas, recifes, cordões litorâneos, falésias e praias, como APPs.

Em Pernambuco, a Lei Estadual $n^{\circ}$ 11.206, de 31 de Março de 1995 (PERNAMBUCO, 1995), que dispõe sobre a Política Florestal do Estado de Pernambuco, em seu art. 10 diz:

Art. 10. Consideram-se, ainda, de preservação permanente. Quando assim declarados por ato do Poder Público, a vegetação e as áreas destinadas a:

(...)

II - fixar as dunas;

(...)

IV - proteger sítios de excepcional beleza ou de valor ecológico, cientifico, histórico e cultural;

(...)

VII - proteger paisagens notáveis;

IX - conservar a biodiversidade.

Pode-se deduzir inicialmente a proteção das dunas fixas e a possibilidade de proteção dos campos dunas móveis, se houver o entendimento que as mesmas se enquadram como "paisagens notáveis". Todavia, essas possibilidades perdem validade ao passo que, em 2012, foi promulgada a Lei no 14.847-2012 (PERNAMBUCO, 2012), que autoriza a supressão de vegetação em Áreas de Preservação Permanente.

\section{Sergipe, Alagoas e Bahia: Litoral Histórico Brasileiro}

Em Sergipe, a Lei Estadual no 5.858, de março de 2006 (SERGIPE, 2006), que dispõe sobre a Política Estadual do Meio Ambiente, institui o Sistema Estadual do Meio Ambiente, apresenta como APPs, as mesmas apresentadas nos artigos $2^{\circ}$ e $3^{\circ}$ da Lei Federal $n^{\circ} 4.771 / 1965$ (BRASIL, 1965), ou seja, considerando as dunas fixas como APPs, e as dunas móveis, bem como as demais feições que compõem o ecossistema dunar, não.

Além disso, a referida lei ainda apresenta em seu art. 92 a possibilidade de supressão de vegetação em área de preservação permanente somente pode ser autorizada em caso de utilidade pública ou interesse social, devidamente caracterizados e motivados em procedimento administrativo próprio, quando 
inexistir alternativa técnica e locacional para o empreendimento proposto (SERGIPE, 2006).

Por sua vez, o estado de Alagoas, através da Lei $\mathrm{n}^{\circ}$ 5.854, de 14 de outubro de 1996, que dispõe sobre a política florestal no estado (ALAGOAS, 1996) cita, em art. 11: “Consideram-se Áreas de Preservação Permanente do Estado, as florestas e demais formas de vegetação natural situadas: (...) IX - nas restingas, como fixadora de dunas ou estabilizadoras de mangues".

Ou seja, novamente tem-se a proteção das dunas fixas. Mais adiante, no seu art. 12, a referida lei estadual diz:

Art. 12 - Consideram-se, ainda, de Preservação Permanente, quando declaradas por ato do Poder Público, as florestas e demais formas de vegetação natural destinadas a:

(...)

c. proteger sítio de excepcional beleza, de valor científico ou histórico;

(...)

g. fixar as dunas;

h. outras consideradas de interesse para a preservação de ecossistemas (ALAGOAS, 1996).

Tal artigo reforça ainda mais a condição das dunas fixas enquanto APPs, abrindo condições para a proteção das demais feições que comumente compõem os ecossistemas dunares. Todavia, conforme visto em outros exemplos, em Alagoas há prerrogativas para supressão da vegetação em APPs.

$\S 1^{\circ}-$ A utilização de Áreas de Preservação Permanente ou de espécies nelas contidas só será permitida mediante prévia autorização do órgão estadual competente, nas seguintes hipóteses:

1 - no caso de obras, atividades, planos e projetos de utilidade de pública ou de interesse social, mediante projeto específico.

2 - na extração de espécimes isoladas, mediante laudo de vistoria técnica que comprove risco ou perigo iminente, obstrução de vias terrestre ou pluviais, bem como para fins técnico-científicos, estes mediante projeto apreciado pelo órgão estadual competente.

3 - para o aproveitamento de árvores, de toras ou de material lenhoso, sem prejuízo da conservação da floresta, com licença específica concedida pelo órgão estadual competente (ALAGOAS, 1996). 
Por fim, em relação ao estado da Bahia, a Lei Estadual n 10.431/2006 (BAHIA, 2006), que dispõe sobre a Política de Meio Ambiente e de Proteção à Biodiversidade do Estado da Bahia, cita em seu art. 89:

\footnotetext{
Art. 89 - Sem prejuízo do disposto na legislação federal pertinente, são considerados de preservação permanente, na forma do disposto no artigo 215 da Constituição do Estado da Bahia, os seguintes bens e espaços:

(...)

IV - as dunas e restingas, sendo que a sua ocupação parcial depende de estudos específicos a serem aprovados por órgão competente;

(..)

$\mathrm{X}$ - as áreas consideradas de valor paisagístico, assim definidas e declaradas por ato do Poder Público.
}

Conforme se observa, a exemplo de outras titulações estaduais, há expressamente a conceituação das dunas e das restingas como APPs, embora com a ressalva de que a ocupação parcial é prevista no mesmo parágrafo. Aliás, essa prerrogativa é reforçada no art. 92 da mesma lei que diz:

Art. 92 - Observado o disposto no parágrafo único do artigo 89 desta Lei, a supressão das espécies, a alteração total ou parcial das florestas e demais formas de vegetação, bem como a ocupação total ou parcial ou qualquer tipo de interferência antrópica nas áreas e bens de preservação permanente, só será permitida nas condições estabelecidas na legislação federal pertinente, nesta Lei e em suas normas regulamentares (BAHIA, 2006).

Por fim, vale citar o parágrafo único do art. 89 que diz que as áreas e bens naturais de que trata este artigo, que não se incluam entre aqueles definidos como Área de Preservação Permanente pela legislação federal, terão seu uso, hipóteses de supressão de vegetação e demais restrições definidos por esta Lei e suas normas regulamentares.

O Quadro 1 apresenta uma síntese dos aspectos apresentados acima nas legislações estaduais, com ênfase nos itens mais relevantes e inter-relacionáveis. 
Quadro 1: Síntese da Legislação Ambiental dos Estados da Região Nordeste

\begin{tabular}{|c|c|}
\hline ESTADO & ASPECTOS RELEVANTES E INTERRELACIONÁVEIS \\
\hline Ceará & $\begin{array}{l}\text { - Sem lei específica sobre APPs. Exceção: eolianitos estabelecidos como APPs } \\
\text { no plano estadual de gerenciamento costeiro. } \\
\text { - Principal diploma legal a respeito: Constituição Estadual. Atenção com a } \\
\text { proteção das praias e das restingas e dunas. } \\
\text { - Entendimento compartimentado entre as praias e as demais feições. Sem } \\
\text { menção explícita às demais feições do ecossistema dunar. }\end{array}$ \\
\hline Maranhão & $\begin{array}{l}\text { - Lei estadual que trata especificamente das APPs (restingas, dunas e as } \\
\text { "paisagens notáveis"). } \\
\text { - Sem distinção entre dunas móveis e dunas fixas. } \\
\text { - Possibilidade de proteção de todo o ecossistema dunar sob a denominação de } \\
\text { "paisagens notáveis". }\end{array}$ \\
\hline Piauí & $\begin{array}{l}\text { - Lei que dispõe sobre a política estadual de meio ambiente não trata sobre } \\
\text { APPs. } \\
\text { - Mesma omissão está presente nos demais diplomas legais vigentes. }\end{array}$ \\
\hline $\begin{array}{l}\text { Rio Grande } \\
\text { do Norte }\end{array}$ & $\begin{array}{l}\text { - Lei estadual que trata especificamente das APPs (dunas móveis e fixas, } \\
\text { restingas, dentre outras). } \\
\text { - Brecha legal para intervenções em APPs. }\end{array}$ \\
\hline Paraíba & $\begin{array}{l}\text { - Assim como ocorre no Ceará, o principal diploma legal é a Constituição } \\
\text { Estadual que traz como APPs diversas feições do ecossistema dunar, tais como: } \\
\text { praias, dunas, restingas e cordões litorâneos. }\end{array}$ \\
\hline Pernambuco & $\begin{array}{l}\text { - Lei estadual que trata sobre a proteção florestal apresenta considerações sobre } \\
\text { APPs, a vegetação e as áreas destinadas à fixação das dunas; à proteção de sítios } \\
\text { de excepcional beleza ou de valor ecológico, cientifico, histórico e cultural; e à } \\
\text { proteção das "paisagens notáveis"; e à conservação da biodiversidade. } \\
\text { - Assim como no Maranhão, há a possibilidade de proteção de todo o } \\
\text { ecossistema dunar sob a denominação de "paisagens notáveis". } \\
\text { - Lei estadual promulgada em } 2012 \text { que permite a intervenção em APPs. }\end{array}$ \\
\hline Sergipe & $\begin{array}{l}\text { - Lei Estadual que dispõe sobre a Política Estadual do Meio Ambiente apresenta } \\
\text { como APPs, as mesmas apresentadas nos artigos } 2^{\circ} \text { e } 3^{\circ} \text { da Lei Federal } n^{\circ} \\
\text { 4.771/1965. Ou seja, apenas as dunas fixas como APPs, excluindo as demais } \\
\text { feições que compõem o ecossistema dunar. } \\
\text { - Mesmo diploma legal apresenta precedentes para a intervenção em APPs. }\end{array}$ \\
\hline Alagoas & $\begin{array}{l}\text { - Lei que dispõe sobre a política florestal apresenta as dunas fixas como APPs, } \\
\text { excluindo as demais feições que compõem o ecossistema dunar. } \\
\text { - Podem também ser consideradas como APPs as formas de vegetação natural } \\
\text { destinadas a: proteger sítio de excepcional beleza, de valor científico ou } \\
\text { histórico; e outras consideradas de interesse para a preservação de ecossistemas. } \\
\text { - Possibilidade de proteção de todo o ecossistema dunar sob a denominação de } \\
\text { "sítios de excepcional beleza". } \\
\text { - Mesmo diploma legal apresenta precedentes para a intervenção em APPs. }\end{array}$ \\
\hline Bahia & $\begin{array}{l}\text { - Lei que dispõe sobre a Política de Meio Ambiente e de Proteção à } \\
\text { Biodiversidade cita as dunas e as restingas enquanto APPs. } \\
\text { - Mesmo diploma legal apresenta precedentes para a intervenção em APPs. }\end{array}$ \\
\hline
\end{tabular}

Geo UERJ - Ano 15, nº. 24, v. 2, $2^{\circ}$ semestre de 2013

ISSN: 1415-7543E-ISSN: 1981-9021

http://www.e-publicacoes.uerj.br/index.php/geouerj 


\section{Conclusões}

O ecossistema dunar abrange em seu compartimento as praias, planície de deflação, dunas móveis, semi-fixas, fixas, eolianitos e paleodunas, sendo que, em âmbito federal, apenas as dunas fixas estão protegidas pelo atual Código Florestal (Lei Federal $n^{\circ}$ 12.651/2012). Ao não caracterizar as demais feições constituintes do ecossistema como APPs, abre-se o precedente legal para sua ocupação, o que pode ocorrer, inclusive, em âmbito estadual, conforme se verifica nos estados do Rio Grande do Norte e de Pernambuco, conforme verificado acima.

O que não pode deixar de ser considerado é que o desequilíbrio das feições naturais não protegidas é sinônimo de desequilíbrio do ecossistema como um todo. Não é demais frisar que deve-se tratar as dunas e as feições correlatas e importantes para sua gênese, migração e estabilização, como um ecossistema único, o qual deve ser mantido ecologicamente equilibrado, sob pena de violação ao que dispõem os princípios do ambiente ecologicamente equilibrado, da prevenção, da precaução, da proteção e da solidariedade intergeracional, que encontram fundamento na Constituição Federal.

Diante disso, torna-se necessário que se considerem legalmente o que a dinâmica ambiental já apresenta, ou seja, as praias, planície de deflação e os diferentes tipos de dunas como um ecossistema. Não custa reiterar que o desequilíbrio das feições naturais não protegidas pela legislação ambiental federal vigente, que se constituem em partes do ecossistema das dunas, é sinônimo de desequilíbrio do ecossistema como um todo, inclusive, portanto, das feições que as leis se propõem preservar.

\section{Agradecimentos}

Os autores agradecem à Fundação Cearense de Apoio ao Desenvolvimento Científico e Tecnológico - FUNCAP pelo apoio concedido através das respectivas bolsas de estudo para apoio ao desenvolvimento das teses de doutorado. 


\section{Referências}

ALAGOAS. Governo do Estado de Alagoas. Lei $\mathbf{n}^{\mathbf{0}}$ 5.854, de 14 de outubro de 1996. Política florestal no Estado de Alagoas. 1996.

BAHIA. Governo do Estado da Bahia. Lei Estadual no 10.431 de 20 de dezembro de 2006. Política de Meio Ambiente e de Proteção à Biodiversidade do Estado da Bahia. D.O.E. de 21.12.2006. 2006.

BRASIL. Decreto-lei no 4.771, de 15 de setembro de 1965. Institui o Novo Código Florestal Brasileiro e dá outras providências. Diário Oficial da União - DOU de 16 de setembro de 1965. Brasília DF. 1965.

BRASIL. Lei Federal $n^{0}$ 6.938, de 31 de agosto de 1981. Dispõe sobre a Política Nacional do Meio Ambiente. 1981.

BRASIL. Lei Federal $n^{0}$ 12.651, de 25 de maio de 2012. Dispõe sobre o Código Florestal. 2012a.

BRASIL. Lei Federal $\mathbf{n}^{\circ}$ 12.727, de 17 de outubro de 2012. Dispõe sobre alterações no Código Florestal. 2012b.

CARVAlHO, A. M; ClaudinO-SAlES, V.; MAIA, L. P.; CASTRO, J. W. A. Eolianitos de Flexeiras/Mundaú, Costa Noroeste do Estado do Ceará, Brasil. Registro Ímpar de um Paleo-sistema Eólico Costeiro. SIGEP. 2008.

CEARÁ. Governo do Estado do Ceará. Lei no 13.796, de 30 de junho de 2006. D.O.E. de 30.06.06. Política Estadual do Gerenciamento Costeiro, 2006.

CEARÁ. Governo do Estado do Ceará. Meio Ambiente: Legislação Básica. Fortaleza: Imprensa Oficial do ceará, 1989.

CHRISTOPHERSON, R. W. Geossistemas: uma introdução à Geografia Física. 7 ed. Porto Alegre: Bookman, 2012.

CLAUDINO-SALES, V. Os Litorais Cearenses. IN: SILVA, J.B; CAVALCANTE, M. T. e DANTAS, E.W.C.(Org.). Ceará: Um novo olhar geográfico. Fortaleza: Demócrito Rocha, 2005.

Les Littoraux Du Ceará. Evolution géomorphologique de la zone côtiére de L'Etat du Ceará, Brésil - Du long terme au court terme. Thése de doctorat, Université Paris-Sorbonne, 511p. 2002. 
GONÇALVES, R. A.; LEHUGEUR, L. G. O.; CASTRO, J. W. A. E PEDROTO, A. E. S. Classificação das Feições Eólicas dos Lençóis Maranhenses, Maranhão, Brasil. Revista Mercator, n 03. Fortaleza: Revista de Geografia da UFC, 2003. MARANHÃO. Governo do Estado do Maranhão. Lei Estadual no 5.405, de 08 de abril de 1992. Código Estadual de Meio Ambiente. 1992.

MMA. Ministério do Meio Ambiente / CONAMA. Conselho Nacional do Meio Ambiente. Resolução CONAMA no 237/1997. Resoluções do CONAMA: resoluções vigentes publicadas entre setembro de 1984 e janeiro de 2012. Brasília: MMA, 2012. p. 644-652.

MOURA-FÉ, M.M. Evolução Geomorfológica do Sítio Natural de Fortaleza. Dissertação de Mestrado (Área de concentração: Dinâmica Ambiental e Territorial). Universidade Federal do Ceará, 2008.

MOURA-FÉ, M. M. e PINHEIRO, M. V. A. Os parques eólicos na zona costeira do Ceará e os impactos ambientais associados. Revista Geonorte. Vol. 9, n. 1, p.22-41, 2013.

PASKOFF, R. Lês Littoraux: Impact dês aménagements sur leur évolution. Paris, Masson, 1996.

PARAÍBA. Governo do Estado da Paraíba. Constituição do estado da Paraíba. João Pessoa: Assembléia Legislativa, 1989.

PEREIRA, T. G.; OLIVEIRA FILHO, S. R.; CORRÊA. W. B.; FERNADEZ, G. B. Diversidade Dunas entre Cabo Frio e o Cabo de Búzios - RJ. Revista de Geografia, n.3, 2010 .

PERNAMBUCO. Governo do Estado de Pernambuco. Lei $\mathbf{n}^{\mathbf{0}}$ 11.206, de 31 de Março de 1995. Política Florestal do Estado de Pernambuco. Recife, 1995.

PERNAMBUCO. Governo do Estado de Pernambuco. Lei $\mathbf{n}^{\circ}$ 14.847, de 22 de novembro de 2012. Autoriza a supressão de vegetação em Áreas de Preservação Permanente, e dá outras providências. 2012.

PIAUÍ. Governo do Estado do Piauí. Lei no 4.854, de 10 de Julho de 1996. Política de Meio Ambiente do Estado do Piauí. Teresina, 1996.

PINHEIRO, M. V. A. Evolução Geoambiental e Geohistórica das Dunas Costeiras de Fortaleza, Ceará. Dissertação de Mestrado (Área de concentração: Dinâmica Ambiental e Territorial). Universidade Federal do Ceará: Fortaleza, 2009. 
RIO GRANDE DO NORTE. Governo do Estado do Rio Grande do Norte. Lei n⿳ $\mathbf{n}^{\mathbf{6}} \mathbf{9 5 0}$, de 20 de agosto de 1996. Plano Estadual de Gerenciamento Costeiro. Natal, 1996. SERGIPE. Governo do Estado de Sergipe. Lei Estadual no 5.858, de 22 de março de 2006. Política Estadual do Meio Ambiente. Aracaju, 2006.

SILVA, M. V. O princípio da solidariedade intergeracional: um olhar do direito Para o Futuro. Veredas do Direito, Belo Horizonte, v.8 n.16 p.115-146, 2011.

SOUZA, M. J. N. Contribuição ao Estudo das Unidades Morfo-estruturais do

Estado do Ceará. Revista de Geologia da UFC. 1:73-91, 1988.

SUGUIO, K. Dicionário de Geologia Sedimentar e Áreas afins. Rio de Janeiro: Bertrand Brasil, 1998.

TESSLER, M. G. e MAHIQUES, M. M. Processos Oceânicos e a Fisiografia dos Fundos Marinhos. IN: TEIXEIRA, W.; TOLEDO, M. C. M; FAIRCHILD, T. R.; TAOLI, F. (Org). Decifrando a Terra. São Paulo. Oficina de Textos, 2003. TOMAZELLI, L.J.; DILLENBURG, S.R.; BARBOZA, E.G.; STRIM, J. O Sistema de Dunas Eólicas Transgressivas do Litoral Norte do Rio Grande do Sul: Situação Atual e Definição de Áreas Prioritárias à Preservação. IX Congresso da Associação Brasileira de Estudos do Quaternário. 2003. TSOAR, H; ARENS, S.M. Mobilização e Estabilização de Dunas em Climas Úmidos e Secos. Revista Mercator 5: 131-144, Fortaleza, 2003.

VILLWOCK, J.B.; LESSA, G.C.; SUGUIO, K; ÂNGULO, R.J. e DILLENBURG, S.R. Geologia e Geomorfologia de Regiões Costeiras. IN: SOUSA, C.R.G. et al. Quaternário do Brasil. Ribeirão Preto: Holos Editora, 2005. 